Journal for ImmunoTherapy of Cancer

\title{
Design, synthesis and immunological evaluation of self-assembled antigenic peptides from dual-antigen targets: a broad-spectrum candidate for an effective antibreast cancer therapy
}

Wei Shi, ${ }^{1}$ Qianqian Qiu, ${ }^{1,2}$ Ziying Feng, ${ }^{1}$ Zhenzhen Tong, ${ }^{1}$ Weiwei Guo, ${ }^{1}$ Feng Zou, ${ }^{1}$ Na Yue, ${ }^{1}$ Wenlong Huang, ${ }^{1,3}$ Hai Qian (i) ${ }^{1,3}$

\section{ABSTRACT}

To cite: Shi W, Qiu Q, Feng Z, et al. Design, synthesis and immunological evaluation of self-assembled antigenic peptides from dual-antigen targets: a broad-spectrum candidate for an effective antibreast cancer therapy. Journal for ImmunoTherapy of Cancer 2021;9:e002523. doi:10.1136/jitc-2021-002523

- Additional online supplemental material is published online only. To view, please visit the journal online (http://dx.doi.org/10.1136/jitc2021-002523).

Accepted 02 May 2021 synthesized.
Check for updates

(C) Author(s) (or their employer(s)) 2021. Re-use permitted under CC BY-NC. No commercial re-use. See rights and permissions. Published by BMJ.

For numbered affiliations see end of article.

Correspondence to Professor Hai Qian; qianhai24@163.com
Background Considering the narrow immune response spectrum of a single epitope, and the nanoparticles (NPs) as a novel adjuvant can achieve efficient delivery of antigenic peptides safely, a nano-system (denoted as DSPE-PEG-Man@EM-NPs) based on cathepsin B-responsive antigenic peptides was designed and

Methods Highly affinitive antigenic peptides were delivered by self-assembled NPs, and targeted erythrocyte membranes acted as a peptide carrier to improve antigenic peptides presentation and to strengthen cytotoxic T-cells reaction. Cathepsin B coupling could release antigenic peptides rapidly in dendritic cells.

Results Evaluations showed that DSPE-PEG-Man@EMNPs had obvious inhibitory effects towards both MCF-7 and MDA-MB-231 human breast cancer cell lines. Conclusion Overall, this strategy provides a novel strategy for boosting cytotoxic T lymphocytes response, thereby expanding the adaptation range of tumor antigenic peptides and improving the therapeutic effect of tumor immunotherapy with nanomedicine.

\section{INTRODUCTION}

Breast cancer is one of the most serious malignant tumors that threaten women's life, and its morbidity has gradually increased in recent years. ${ }^{12}$ Although the mortality rate of breast cancer has gradually decreased with the development of early diagnosis and comprehensive treatment, there is still a high probability of metastasis and recurrence, which is possibly related to mechanisms of resistance, regulation of relevant signaling pathways and activation of oncogenes. ${ }^{34}$ Recent studies found that regulating interrelation between immune system and tumor microenvironment of hosts and investigating its corresponding mechanism can provide some clues for the treatment of breast cancer. ${ }^{56}$ At present, researches of immunotherapy on breast cancer mainly focuses on vaccines, chimeric antigen receptor-engineered $\mathrm{T}$ lymphocytes and immune checkpoint inhibitors. ${ }^{7-10}$ Additionally, due to the influence of tumor staging, individual immune status, and mutations, there are more and more claims about the precision treatment, but the difficulty and cost of that are certain. Compared with other immunotherapies in development, the peptide vaccine that is artificially synthesized using an epitope peptide of a tumor specific antigen, is more convenient. It can be effectively recognized by the antigen presenting cells (APCs) and directly bind to the major histocompatibility complex (MHC) molecules, thereby activating $\mathrm{T}$ lymphocytes, and inducing strong specificity. ${ }^{11-13}$ Since the discovery of tumor-specific antigens by Boon et al, many tumor antigens have been found, and relevant cytotoxic T lymphocytes (CTLs) epitopes have been identified. ${ }^{14}$ Many synthetic peptide vaccines such as melanoma antigen (MAGE), New York esophageal squamous cell carcinoma-1 (NY-ESO-1), human papillomavirus HPV16 E7 synthetic peptides, oncogenes, peptide fragments of tumor suppressor gene products and mucin have been reported. ${ }^{16-20}$ For example, Eikawa et al found a 20-mer NY-ESO-1 peptide harboring multiple $\mathrm{CD}^{+} \mathrm{T}$ lymphocyte epitopes useful as an NY-ESO-1 vaccine. ${ }^{21}$ Shi et al reported that pMAGE-A1(278-286) epitope might serve as a surrogate tumor antigen target of specific immunotherapy for treating human leucocyte antigen-A2 (HLA-A2) patients with malignant glioma. ${ }^{22}$ Rahma et al demonstrated the feasibility and ability of preimmature dentritic cells (DCs) pulsed with HPV16 E6 (18-26) or HPV16 E7 (12-20) for inducing a specific immune response against 
relevant peptide. ${ }^{23}$ Various studies have shown that the vaccines are safe and specific, but their failure in clinical trials still exists mainly because of the following reasons.

First, the regulatory mechanism behind the immune response is complex. Tumor cells will spontaneously downregulate or lose some of the surface antigen epitopes (called antigen modulation) due to a basic instinct to protect themselves. ${ }^{24}$ Consequently, CTLs are disabled to effectively identify tumor cells, and organism could not be protected from damage. ${ }^{25}$ Moreover, the immunogenicity of antigenic peptides would fail to function normally because of the weak binding between antigenic peptides and the MHC molecules. ${ }^{26}$ To solve the above problems, we designed a delivery system which using cathepsin B-responsive dipeptide to covalently link antigenic peptides MAGE and NY-ESO-1. The antigenic online supplemental peptides 1 and 2, with excellent affinity to HLA-A2 were obtained in our previous studies via structural modification. ${ }^{27} 28$ Such combination between different kinds of antigenic peptides could effectively ameliorate the single epitope escape phenomenon and increase immune response as well.

Moreover, weak immunogenicity is also the critical factor leading to the clinical failure of multiple tumor peptide vaccines. To improve the weak immunogenicity, adjuvants which can greatly augment the immune efficacy are widely used and become more and more important. ${ }^{29}{ }^{30}$ Common adjuvants such as aluminum salt adjuvant can only enhance the humoral immunity but not cellular immunity. Additionally, when the dose exceeds a certain content, it may cause adverse effects to organisms by being considered as a reactionogen, thus limiting its clinical application. ${ }^{31}$ Recently, with the interdisciplinary development between immunology and physical chemistry, nanoparticulate adjuvants have attracted much attention. ${ }^{32}$ Nanoparticles (NPs) were formed in this study from the self-assembly of amphiphilic covalently linked molecules, and they can protect the antigenic peptides from degradation. This system can also release the antigenic peptides at the immunization site to prolong the duration of immunity simultaneously, thereby inducing APCs to produce cytokines and promoting lymphocytes activation.

Furthermore, DCs, the only known APC in vivo that could induce primary immune responses and activate unsensitized $\mathrm{T}$ lymphocytes, have been the focus of research on tumor immunotherapy. ${ }^{34}$ Enhancing the effective uptake of tumor antigens by immature DCs is a key step in improving the antigen presentation and in exerting an immune response. The mannose receptor is a C-type lectin receptor, which is highly expressed on the DCs membrane surface. It can internalize antigens and induce immune response. ${ }^{35}$ Research showed that using mannose-modified liposomes as carriers to load tumor antigens can improve the stability of tumor antigens in vivo and the uptake efficiency of DCs to tumor antigens. ${ }^{36}$ Self-assembled NPs are easy to be removed by the reticuloendothelial system (RES) dominated by macrophages in vivo, ${ }^{37}$ and cannot reach DCs effectively and bind with the MHC-I molecules highly expressed on human DCs. Erythrocyte membranes are widely used as a drug carrier because of its advantages including good biocompatibility and degradability, no toxicity, simple structure and easy preparation, sufficient source and suppression of the RES phagocytosis. ${ }^{38} 39$ Additionally, the erythrocyte membranes phospholipid bilayer can also be introduced with different targeting proteins to achieve an active targeting effect of the nano drug-carrier system. ${ }^{40-43}$ In particular, CD58 and CD59 proteins on erythrocyte membranes can promote immune recognition and the antigen presentation. ${ }^{44}$ Therefore, erythrocytes, as antigen carriers, can enhance the antigen presentation and induce CTLs responses. In this study, the powerful delivery carrier, DSPE-PEG-Man@EM-NPs, was constructed based on cathepsin B-responsive antigenic peptides encapsulated by erythrocyte membranes to achieve an efficient delivery of antigenic peptides with a high affinity to HLA-A2. The covalent attachment of different antigenic peptides improved antigen modulation and reduced immune escape. Cathepsin B coupling was used to achieve rapid release in DCs. This targeting delivery system of antigenic peptides exhibited specific DCs cellular uptake and responsive drug release, which greatly inhibited the growth of tumor in both MDA-MB231 and MCF-7 human breast cancer cell lines. Therefore, the precise treatment here does not represent one-to-one customized treatment process, nor is it contrary to the general application. On the contrary, it is the a relatively efficient and ideal scheme to accurately group patients and treat a group of patients with common characteristics using this targeting delivery system.

\section{EXPERIMENTAL SECTION \\ Materials}

Wang resin was purchased from Lanxiao Technology (Xi'an, China). Fmoc-protected amino acids and 1-Hydroxy-1H-benzotriazole were purchased from Jill Biochemical (Shanghai, China). Trimethylsilane and dimercaptoethane (EDT) were obtained from Sahn Chemical Technology (Shanghai, China). N, N-diisopropyl ethylamine was purchased from Kangmanlin Chemical Industry (Nanjing, China). Thioanisole, dithioglycol, trifluorocarboxylic acid and formic acid for mass spectrometry were purchased from Acladin Biochemical Technology (Shanghai, China). Piperidine, N, N-dimethylformamide were obtained from Haibang Trading (Nanjing, China). Dichloromethane, N-methylpyrrolidone, phenol, and bromophenol blue, and coomassie brilliant blue G-250 were purchased from Sinopharm Group Chemical Reagent (Shanghai, China). Acetonitrile and methanol (HPLC grade) were obtained from Merck (Darmstadt, Germany). Unless indicated, all other reagents were purchased from Sigma-Aldrich (St Louis, Missouri, USA). Peptides were synthesized using manual solid-phase peptide 
synthesis under the protection of nitrogen, and the mass of obtained peptides and target conjugates were confirmed by Waters ACQUITY UPLC Systems (Waters, Milford, Massachusetts, USA).

\section{CELL LINE AND CELL CULTURE}

All cell lines used in this study (T2, MDA-MB-231, MCF-7, MCF-10A) were obtained from Gaining Biotechnology (Shanghai, China) and KeyGEN BioTECH (Nanjing, China), respectively. The cells were cultured with appropriate medium according to ATCC at $37^{\circ} \mathrm{C}$ in a humidified atmosphere under $5 \% \mathrm{CO}_{2}$ and $95 \%$ air. Human peripheral blood mononuclear leucocyte was obtained from Jiangsu blood center. All the blood-related experimental protocols were approved by an ethical committee at the China Pharmaceutical University and conducted according to related laws and regulations.

\section{ANIMALS}

Female tumor-bearing BALB/c nude mice (6-8 weeks old) were purchased from Cavens Laboratory Animal Technology (Chang Zhou, China). All mice were maintained under specific pathogen-free condition in the animal center of the China Pharmaceutical University. The animals were maintained at $25 \pm 1{ }^{\circ} \mathrm{C}$ and $60 \% \pm 10 \%$ humidity under a 12-hour light/dark cycle during the experiments. All experimental protocols for animals were approved by an ethical committee at the China Pharmaceutical University, conducted according to the Laboratory Animal Management Regulations in China and adhered to the Guide for the Care and Use of Laboratory Animals published by the National Institutes of Health (revised 2011). Experiments were conducted in such a way that the number of animals used and their suffering was minimized.

\section{Preparation of the self-assembled NPs}

The fusion of hydrophilic MAGE-A1 (online supplemental peptide 1), CB-sensitive dipeptide (Val-Cit), and hydrophobic NY-ESO-1 (online supplemental peptide 2) were obtained by Fmoc solid-phase peptide synthesis. The as-prepared compounds were purified by C18 reverse chromatography column (model: Shimadzu LC-6A, chromatographic column: C18 reversed-phase LC column $(5 \mu \mathrm{m}, 340 \times 28 \mathrm{~mm}$, Shimadzu, Japan), mobile phase A: $0.1 \%$ trifluoroacetic in $100 \%$ water, mobile phase B: $0.1 \%$ trifluoroacetic in $100 \%$ acetonitrile, detection wavelength: $214 \mathrm{~nm}$, velocity: $5 \mathrm{~mL} / \mathrm{min}$ ). Subsequently, the fusion peptide was dissolved in a small amount of methanol/acetone by ultrasound and then dripped into ultrapure water. The organic solvents were removed by decompressing concentration, where only the aqueous phase was retained. Finally, the self-assembled NPs dispersed in ultrapure water was obtained.
Preparation of erythrocyte membranes, EM-NPs, and DSPEPEG-Man@EM-NPs

Preparation of erythrocyte membranes. (1) Anticoagulant venous blood of mice was mixed with $3 \%$ gelatin saline solution. (2) The test tube/centrifugal tube was placed upright at room temperature for $60 \mathrm{~min}$, where the adhesion between gelatin and erythrocytes was used to promote the rapid sinking of erythrocytes, while the white blood cells remained in gelatin solution. (3) Erythrocytes were placed in three times the amount of precooled isotonic normal saline, mixed slowly, and centrifuged at $4^{\circ} \mathrm{C}, 5000 \mathrm{r} / \mathrm{min}$ for $15 \mathrm{~min}$. Then, the supernatant and sediment surface were removed, and washed for three times. (4) The obtained erythrocytes were mixed with pre-cooled $10 \mathrm{mmol} / \mathrm{L} \mathrm{pH} 7.4$ low osmotic Tris-hydrochloric acid buffer at the ratio of 1:40, and placed at $4{ }^{\circ} \mathrm{C}$ for 2 hour to complete hemolysis. The erythrocyte membranes were precipitated by centrifugation at $9000 \mathrm{r} / \mathrm{min}$ for $15 \mathrm{~min}$. After repeated washing and centrifugation for five times, off-white erythrocyte membranes were prepared.

Preparation of EM-NPs. The self-assembled NPs were mixed with the freeze-dried powder of erythrocyte membranes at a mass ratio of 2:1, and obtained by intermittent ultrasound 10 times per minute. This ratio is the best ratio finally determined according to literature reports ${ }^{40} 45$ and combined with my own various conditions (online supplemental table S1). Preparation of DSPE-PEG-Man@EM-NPs. DSPE-PEG-Man (40 $\mu \mathrm{g})$ was incubated with the above-mentioned EM-NPs at room temperature for $45 \mathrm{~min}$, centrifuged for $20 \mathrm{~min}$ at $9000 \mathrm{rpm}$, washed twice by PBS and dispersed for reserve.

\section{Characterizations of the different NPs}

To further verify successful coating of erythrocyte membranes on NPs, the transmission electron microscope (TEM, JMPEG-PTMC-1230, JEOL, Japan), dynamic light scattering (DLS), and sodium dodecyl sulfatepolyacrylamide gel electrophoresis (SDS-PAGE) were analyzed in succession. TEM: The NPs solution with appropriate concentration was dropped on a special copper mesh, and water was dried under infrared irradiation. A drop of phosphomolybdic acid was added for staining. Afterwards, the morphologies of the self-assembled NPs and EM-NPs were observed separately. DLS: The size distribution and zeta potential of NPs were performed using a Malveb Zetasizer (Nano-ZS90, Malvern Instruments, UK) with a He-Ne ion laser of $633 \mathrm{~nm}$. In addition, the Tyndall effect, size distribution, and cathepsin $B$ responsiveness of the self-assembled NPs from doubleantigenic peptides were further studied after the action of Cathepsin B. The fusion polypeptide ( $2 \mathrm{mg}$ ) was dissolved in a $10 \mathrm{~mL}$ of sodium acetate-sodium buffer $(25 \mathrm{mM}, \mathrm{pH}$ $5.0)$ to prepare a nano-solution at a concentration of $0.2 \mathrm{mg} / \mathrm{mL}$, and $50 \mu \mathrm{L}$ of cathepsin B in sodium acetate buffer $(50 \mathrm{UI} / \mathrm{mL})$ was added. The enzyme solution was previously activated by $100 \mu \mathrm{L}$ of $30 \mathrm{mM}$ Dithiothreitol (DTT) $/ 15 \mathrm{mM}$ Ethylenediamine (EDTA) solution for 
15 min. Then the self-assembled NPs solution was incubated with cathepsin B for 1 hour. Tyndall effect, particle size distribution, and liquid phase purity were evaluated.

\section{Stability evaluation of the self-assembled NPs, EM-NPs and DSPE-PEG-Man@EM-NPs}

First, $2 \mathrm{~mL}$ of PBS solution with the self-assembled NPs, EM-NPs as well as DSPE-PEG-Man@EM-NPs was obtained. The particle size distribution as well as zeta potential was measured on the 1st to 7 th day, where the mixing uniformity should be ensured before testing. Meanwhile, the plasma stability of the self-assembled NPs was studied in vitro. The target compound was dissolved in Tris-HCl buffer (0.01 M, pH 7.4, BioScience, Shanghai) and disposed into $1000 \mathrm{ng} / \mathrm{mL}$ mother solution. The rat plasma and the solution to be tested was mixed $(300 \mu \mathrm{L}$ each), and incubated in $37^{\circ} \mathrm{C}$ for $0,2,5,10,30,60 \mathrm{~min}$. Then $50 \mu \mathrm{L}$ of mixture was taken out at each time point and $100 \mu \mathrm{L}$ of methanol was added to precipitate the protein. After centrifuging at $12000 \mathrm{rpm}$ for $15 \mathrm{~min}$, the supernatant was collected and centrifuged again for 10 min. Subsequently, the peak area of mass spectrometry was integrated by UPLC-MS to obtain the plasma half-life. Furthermore, a batch of DSPE-PEG-Man@EM-NPs sample at $1 \mathrm{mg} / \mathrm{mL}$ was randomly chosen, after the in vitro digestion, the corresponding characteristic peak was obtained through the liquid phase, where the standard solution at $1 \mathrm{mg} / \mathrm{mL}$ was served as control, and the general weight ratio of each ingredient in DSPE-PEG-Man@EM NPs was obtained.

\section{Evaluation of protein expression on erythrocyte membranes}

EM-NPs were centrifuged for $30 \mathrm{~min}$ at $12000 \mathrm{rpm}$. The precipitation was decomposed on ice for $30 \mathrm{~min}$. The supernatant was centrifuged at $4^{\circ} \mathrm{C}, 12000 \mathrm{r} / \mathrm{min}$ for $20 \mathrm{~min}$. The total protein was extracted. The single erythrocyte membranes were used as controls. Subsequently, the total protein was boiled with $5 \times$ SDS-Loading Buffer (volume ratio $4: 1$ ) at $95^{\circ} \mathrm{C}$ for $5 \mathrm{~min}$, cooled down to room temperature, and stored at $-80^{\circ} \mathrm{C}$. Afterwards, SDSPAGE was carried out according to the method reported in the literature ${ }^{46}$ which proceed under $80 \mathrm{~V}$ for 2 hours, and stained with coomassie brilliant blue G-250. Then, the separation of protein bands was observed according to the protein maker. The transmembrane procedure was performed under $200 \mathrm{~mA}$ for 2 hours. The membrane was blocked with $5 \%$ bovine serum albumin for $40 \mathrm{~min}$, incubated with the primary antibody and secondary antibody in succession, and ECL kit was used to detect primary antibody with Bio-Rad Exposure System. ${ }^{40}$

\section{Acquisition of peripheral blood-derived DCs and $\mathrm{CD}^{+} \mathrm{T}$ lymphocytes}

After removal of non-adherent $\mathrm{T}$ lymphocytes, PBMCs were seeded in culture flasks at a density of $1 \times 10^{5}$ / $\mathrm{mL}$ and cultured in RPMI-1640 medium containing $10 \%$ Fetal bovine serum (FBS), recombinant human granulocyte-macrophage colony-stimulating factor
(rhGM-CSF) (100 ng/mL, Novoprotein, Hefei, China) and recombinant human interleukin (rhIL)-4 (100 ng/ $\mathrm{mL}$, Novoprotein, Hefei, China). The medium was changed every 2 days and cytokines were added. Recombinant human tumor necrosis factor $\alpha(\mathrm{TNF}-\alpha)(100 \mathrm{ng} /$ $\mathrm{mL}$, Novoprotein, Hefei, China) was supplied starting on the fifth day to further maintain DCs' viability. Moreover, HLA-A2 positive peripheral blood samples were taken, and set as the negative control group, the CD8 (FITClabeled, BD Pharmingen, USA) single staining group, the CD3 (PerCP-labeled, Multi Sciences (lianke) Biotech) single staining group, and $\mathrm{CD} 8 / \mathrm{CD} 3$ double staining group. FITC-labeled anti-human CD8 $(20 \mu \mathrm{L})$ and PerCPCyanine 5.5-labeled anti-human CD3 $(20 \mu \mathrm{L})$ were added to the suspension and incubated at $4{ }^{\circ} \mathrm{C}$ for $30 \mathrm{~min}$ in the dark. After centrifugation at $4^{\circ} \mathrm{C}, 2000 \mathrm{rpm}$ for $10 \mathrm{~min}$, the supernatant was discarded, and the cells were resuspended in PBS containing 2\% FBS. CD8+ T lymphocytes were obtained by a flow sorting device (BD FACSAria II SORP, San Jose, California, USA).

\section{Evaluation of erythrocyte membranes mediated macrophages escape in vitro}

To quantify the uptake by RAW 264.7 cells, self-assembled NPs and EM-NPs were stained with DiI (Beyotime Biotechnology, Nanjing, China) for $30 \mathrm{~min}$, RAW 264.7 cells $\left(2 \times 10^{5}\right.$ cells/well) were seeded in a 6 -well plate, and cultured for 24 hours. Then the NPs were washed twice, and cells were incubated with DiI-labeled self-assembled NPs and EM-NPs before incubating for 4 hours. Afterwards, the cells were washed with PBS for three times. One half of cells were used for a flow cytometry (FACS, BD Accuri C6, USA), and the other half were stained with Hoechst 33258 (Beyotime Biotechnology, Nanjing, China) for $30 \mathrm{~min}$. After washing with PBS, the cells were imaged by an inverted fluorescence microscope (Ts2R, Nikon, Japan).

\section{Study on uptake of EM-NPs by DCs}

Inverted fluorescence microscope: $500 \mu \mathrm{L}$ of selfassembled NPs, EM-NPs, and DSPE-PEG-Man@EM-NPs with the concentration of $10 \mu \mathrm{g} / \mathrm{mL}$ were incubated with peripheral blood-derived DCs for 4 hours in 6-well plates (all the NPs were prestained with DiI). The cells were washed twice with cooled PBS and then subjected to nuclear staining with Hochest $33258(10 \mu \mathrm{g} / \mathrm{mL})$. After another twice washing, DCs were resuspended in PBS, and the fluorescence was observed by an inverted fluorescence microscope.

Flow cytometer: DCs were seeded in a 6 -well plate at a density of $2 \times 10^{5} / \mathrm{mL}$, placed at $37^{\circ} \mathrm{C}$ in a humidified atmosphere with $5 \% \mathrm{CO}_{2}$ overnight, and the medium was discarded next day. After washing with cooled PBS, the NPs solution at the concentration of $1 \mu \mathrm{g} / \mathrm{mL}$ was added (all the NPs were pre-stained with DiI), which was divided into self-assembled NPs group, EM-NPs group, and DSPEPEG-Man@EM-NPs group. After overnight incubation at 
room temperature, the cells were washed twice and resuspended in $300 \mu \mathrm{L}$ PBS for flow detection.

\section{Study on the maturation of DCs by NPs}

DCs are recognized as the most potent APCs. The immature DCs would become mature after antigens uptake, then DCs' surface markers such as CD86 and CD11c, and the extracellular IL-12 secretion would increase. Herein, to evaluate the maturation status, DCs were collected and cultured with different NPs $(100 \mu \mathrm{M})$ and cytokines (rhIL-4 and rhGM-CSF, $100 \mathrm{ng} / \mathrm{mL}$ ) for 24 hours. In addition to observing the morphology, the single cell suspension with a density of $1 \times 10^{6} / \mathrm{mL}$ was prepared. Anti-CD86 (2.5 $\mu \mathrm{L}$, eBioscience Biotechnology, Shanghai, China) and anti-CD11c $(2.5 \mu \mathrm{L}$, eBioscience Biotechnology, Shanghai, China) were added to each group and incubated at $4{ }^{\circ} \mathrm{C}$ for $40 \mathrm{~min}$. After washing and centrifuging $(2000 \mathrm{r} / \mathrm{min}, 5 \mathrm{~min})$, the cells were suspended in a $300 \mu \mathrm{L}$ of PBS for a flow cytometry. Moreover, the secretion level of IL-12 was determined using a Human IL-12 ELISA Kit (SenBei Jia Biological Technology).

\section{Effect of NPs on activation of CD8 ${ }^{+}$T lymphocytes}

Interferon gamma (IFN- $\gamma$ ) and $\mathrm{TFN}-\alpha$ are regarded as two of the strongest signals for CD8 +T lymphocytes' activation, so their secretion levels were determined using a Human IFN- $\gamma$ ELISA kit (Wuhan Jiyinmei Biological Engineering) and a Human TFN- $\alpha$ ELISA kit (SenBei Jia Biological Technology). The amounts of IFN- $\gamma$ and TNF- $\alpha$ secreted in the supernatant were detected by co-incubation of DCs treated with different NPs and CD8+ T lymphocytes.

\section{Effect of NPs on CTLs activity}

After CD8 + T lymphocytes were activated, they can exert their cytotoxic effects and inhibit the growth of tumor cells expressing the target antigens. Herein, MCF-7 cells, MAD-MB-231 cells, MCF-10A cells, and T2 cells were set as target cells, while DCs carrying different analytes and CD8 + T lymphocytes (at the volume of 10:1) were disabled as effector cells. Then, the activity of CTLs was detected according to the operating instructions of CytoTox 96 (Promega) kit (Promega, USA). ${ }^{47}$

\section{In vivo antitumor effect of NPs}

Mechanistically and from the in vitro evaluation results, after the NPs assembled from tumor-specific antigenic peptides were uptaken by immature DCs, the antigenic peptides from two different tumor antigens were released, and then promoted the maturation and function of DCs. DCs loaded with antigenic peptides could stimulate activation of $\mathrm{CD}^{+} \mathrm{T}$ lymphocytes (CTLs). After that, the tumor-specific receptors on the surface of antigen specific CTLs would recognize the antigens expressed by tumors and then directly kill tumors or mediately make tumors apoptosis. To verify the in vitro tumor inhibitory effect of the superior experimental groups (NPs), and investigate the in vivo tumor inhibition induced by activation of CD8 + T lymphocytes by the self-assembled NPs, EM-NPs, and DSPE-PEG-Man@EM-NPs, BALB/c nude mice inoculated underarm with MCF-7 or MDA-MB-231 breast cancer cells were used. After 1 week of normal feeding, the tumor diameter reached about $0.6 \mathrm{~cm}$. Tumor-bearing nude mice were randomly divided into five groups, and five mice for each group (here, the dose used has been calculated to ensure that the initial dose of self-assembled NPs was constant, and the final concentration was $100 \mu \mathrm{M}$ ), where PBS was set as a blank control, $\mathrm{CD} 8^{+} \mathrm{T}$ lymphocytes as a negative control to demonstrate the lethal effect of T lymphocytes was specific, while the experimental group was a mixture of $\mathrm{CD} 8^{+}$ T lymphocytes and DCs loaded with different NPs. Tumor size and weight of mice were monitored every day after in situ injection of target substance. Then the mice were killed by neck amputation, and tumors were collected. Subsequently, further measurements were made to characterize the inhibition effect of different NPs towards the growth of tumors in vivo. Tumor inhibition curve was plotted by Graphpad Prism V.6.0, and the tumor inhibition rate was calculated.

Where the tumor volume $=1 / 2 \mathrm{ab}^{2}$ ( $\mathrm{a}$ is the length of tumor and $\mathrm{b}$ is the width of tumor). (\%)Tumor inhibition $=\left(\right.$ tumor weight ${ }_{\text {control group }}-$ tumor weight $\left.{ }_{\text {experimental group }}\right) /$ tumor weight ${ }_{\text {control group }} \times 100 \%$.

\section{Evaluation of systemic toxicity in vivo}

After being sacrificed by cervical dislocation, the lung, kidney, liver, and spleen of the above-mentioned mice were simultaneously peeled off for HE staining. Histopathological sections were done in the company of Nanjing Dizhao Biotechnology. The slices were observed to evaluate whether the target NPs had potential safety hazards to important organs in the body.

\section{RESULTS}

\section{Design of DSPE-PEG-Man@EM-NPs}

As demonstrated in figure 1, the hydrophilic tumor-specific MAGE antigenic peptide (online supplemental peptide 1) and the hydrophobic tumor-specific NY-ESO-1 antigenic peptide (online supplemental peptide 2) that could bind to HLA-A2 tightly were selected and covalently linked to each other via a cathepsin B-responsive dipeptide (Val-Cit). Amphiphilicity was thus constructed in the fusion molecule which could further self-assemble into NPs. The DCs-targeted mannose was used to modify the mice-derived erythrocyte membranes, and the NPs encapsulated with target-labeled erythrocyte membranes (DSPE-PEG-Man@EM-NPs) was obtained and used as a biocompatible nanodelivery system of tumor antigenic peptides for DCs processing. This delivery system could be efficiently taken up by dendritic cells through receptor-mediated endocytosis, and bind to HLA-A2 molecules to further promote $\mathrm{CD}^{+} \mathrm{T}$ lymphocytes, thus inhibiting specific tumors in vivo.

\section{Preparation and characterization of the self-assembled NPS and EM-NPs}

DCs, as a special type of APCs, are short of many organelles and enzymes compared with typical monocytes. It is well known that phagocytic vesicles of NPs would be formed and bound to lysosome after DCs ingesting pathogens. ${ }^{4849}$ 


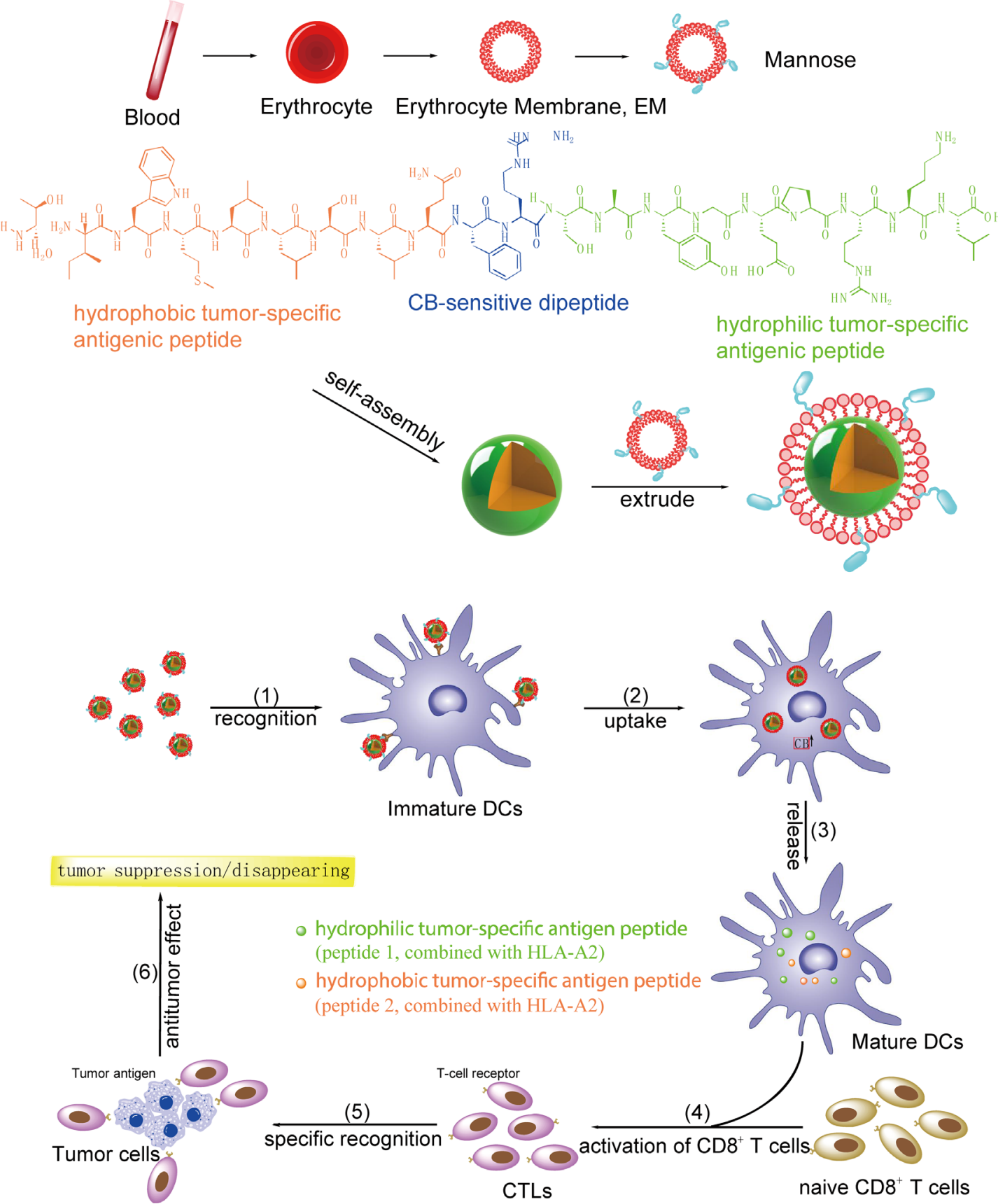

Figure 1 Schematic design of DSPE-PEG-Man@EM-NPs. (1) DSPE-PEG-Man@EM-NPs are recognized by the mannose receptor on DCs surface. (2) DSPE-PEG-Man@NPs are uptaken by DCs. (3) Under the action of high concentration cathepsin B in DCs, antigenic peptides release and bind to HLA-A2 to promote DCs maturity. (4) Naive CD8 ${ }^{+}$T lymphocytes are stimulated by mature DCs and then become CTLs. (5) T-cell receptors specifically recognize tumor cells expressing target antigens. (6) CTLs play a critical role in an antitumor immune response. CTLs, cytotoxic T lymphocytes; DCs, dentritic cells; HLA-A2, human leucocyte antigen-A2.

In order to expand the scope of immune response to different types of breast cancer, the two-segment peptide sequences were first linked. The formed fusion molecule would be recognized by cathepsin B making it an intelligent nano-system for delivery of antigenic peptides when ingested by DCs. Specifically, the hydrophilic and hydrophobic antigenic peptide fragments on different targets were linked by the cathepsin B-sensitive dipeptide linker, Val-Cit. By solvent evaporation method, the hydrophilic end of the amphiphilic molecule interacted with water through hydrophilic interaction forming an interface, and the hydrophobic end of the molecule aggregated inward forming self-assembled NPs. The size distribution and TEM results (figure 2A,B) showed that the self-assembled NPs had a spherical particle size of roughly $155 \mathrm{~nm}$, and a bright channel could be observed in the aqueous solution under the irradiation of laser (figure 2C). As expected, the self-assembled NPs precipitated obviously and the 

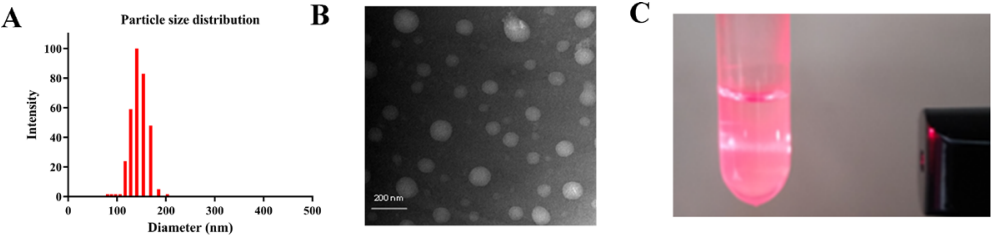

D

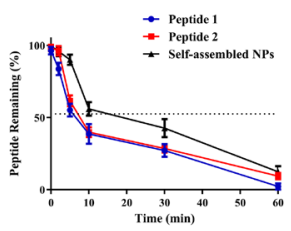

E

$\mathbf{F}$

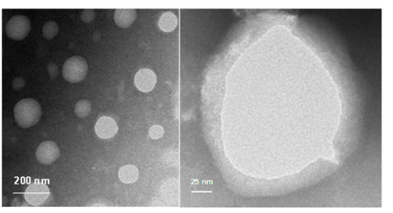

G

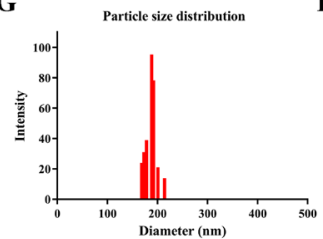

$\mathbf{H}$

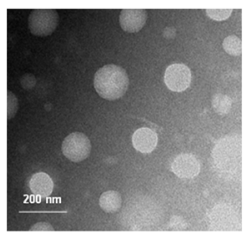

I

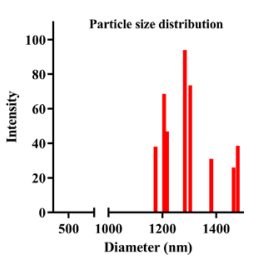

M

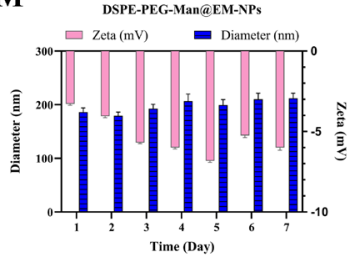

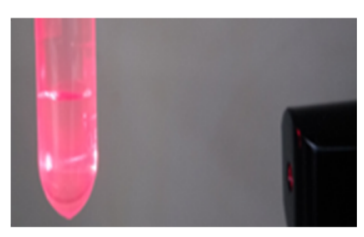

N $\quad$ MW (kDa)
K

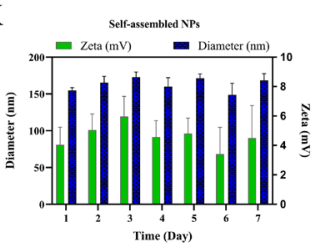

$\mathbf{L}$

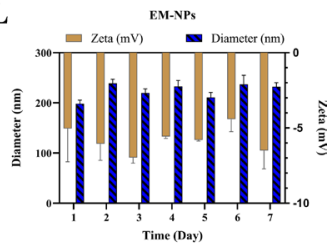

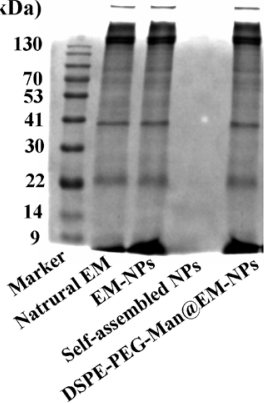

Figure 2 (A) Particle size distribution and morphology of self-assembled NPs from antigenic online supplemental peptides 1 and 2; (B) The morphology of the self-assembled NPs; (C) The Tyndall effect of the self-assembled NPs; (D) Assessment of plasma stability of self-assembled NPs compared with the single peptides $(n=3)$; (E) Particle size and (F) Morphology of the self-assembled NPs encapsulated with erythrocyte membranes (EM-NPs); (G) Particle size and (H) Morphology of the DSPEPEG-Man@EM-NPs; (I) Particle size distribution and (J) The Tyndall effect of the self-assembled NPs after coincubation with cathepsin B; (K) Size and potential stability of the self-assembled NPs in phosphate buffered solution (PBS) ( $n=3)$; (L) Size and potential stability of EM-NPs in PBS ( $n=3)$; (M) Size and potential stability of DSPE-PEG-Man@EM-NPs in PBS ( $n=3)$; (N) Evaluation of CD58 and CD59 proteins expression on erythrocyte membranes. NPs, nanoparticles.

Tyndall phenomenon disappeared under the action of cathepsin B (figure 2I,J). Liquid phase spectra further confirmed that the fusion peptide fragment disconnected responsively under the action of cathepsin B (see details in online supplemental materials).

\section{Characterizations of EM-NPs and DSPE-PEG-Man@EM-NPs}

After the EM-NPs and DSPE-PEG-Man@EM-NPs were prepared, the morphology was analyzed by particle size distribution and TEM. The results shown in figure $2 \mathrm{E}, \mathrm{F}$ indicated that the size distribution of EM-NPs was relatively uniform (roughly $185 \mathrm{~nm}$ ), the size distribution of DSPE-PEG-Man@EM-NPs was roughly equivalent to that of EM-NPs (figure 2G,H), where characteristic membrane shell structure could be observed under TEM in both NPs. Compared with the precell membranes, the particle size increased slightly, which was consistent with those reported in literature. ${ }^{50}$

\section{Stability of DSPE-PEG-Man@EM NPs in vitro}

The in vitro stability of the self-assembled NPs from double-antigenic peptides, the EM-NPs, and DSPEPEG-Man@EM-NPs in PBS were investigated for 1 week (figure 2K-M). The NPs were placed in isotonic PBS within 7 days, and the particle size and zeta potential did not change significantly. The particle size and zeta potential of the self-assembled NPs was distributed roughly $165 \mathrm{~nm}$ and $4.6 \mathrm{mV}, 200 \mathrm{~nm}$ and $-5.76 \mathrm{mV}$ for EM-NPs, $205 \mathrm{~nm}$ and $-5.29 \mathrm{mV}$ for DSPE-PEG-Man@EM-NPs, respectively. This indicated that aggregation did not occur in the body fluid environment for the as-prepared NPs, thus ensuring a successful drug delivery process.

\section{Protein expression on erythrocyte membranes}

Erythrocytes are the most abundant natural immune cells in human blood circulation and immune system. ${ }^{51}$ CD58 and CD59 are both expressed on the surface of 
erythrocytes, and they have the ability to stimulate $\mathrm{T}$ lymphocytes. ${ }^{52}$ Hence, to observe the relative integrity of proteins on the erythrocyte membranes before and after encapsulation of NPs, SDS-PAGE was used to determine the main bands in EM-NPs and DSPE-PEG-Man@ EM-NPs groups according to the literature. ${ }^{40}$ As shown in figure $2 \mathrm{~N}$, the main protein bands in the above two groups were basically the same as those in single erythrocyte membranes group, while no corresponding bands were found in the self-assembled NPs. Moreover, the expressions of CD58 and CD59 were analyzed qualitatively by Western blotting to validate the specific antigens. The results showed that both of them were retained before and after encapsulation, and the EM-NPs and DSPE-PEG-Man@EM-NPs were stable enough to apply in biomedical conditions.

\section{Improvement of plasma stability of antigenic peptides by self- assembled NPs}

The short half-life of most peptide vaccines is one of the reasons for the inadequate immune effects induced in vivo. In this study, we simulated the metabolism of compounds in vivo through in vitro plasma stability experiments. The concentrations of compounds at different time points were measured by Ultra performance liquid chromatography-MS/MS (UPLC-MS/MS), and the plasma half-life was calculated. As shown in figure 2D, the half-lives of online supplemental peptides 1 and 2 were about $5 \mathrm{~min}$, while the half-life of the self-assembled NPs was significantly prolonged by more than three times, thereby suggesting that this self-assembly strategy could improve the plasma stability of antigenic peptides. Furthermore, according to the ratio of each characteristic peak after enzymatic hydrolysis to the liquid phase peak of the standard samples, the general weight ratio of each ingredient in DSPE-PEG-Man@EM-NPs was 25:12.5:1 (self-assembled NPs: EM: DSPE-PEG-Man).

\section{Improvement of macrophage phagocytosis of self-assembled NPs}

NPs would be engulfed by macrophages as foreign bodies. ${ }^{53}$ To verify the EM-NPs can effectively reduce the phagocytosis of macrophages in vitro as reported ${ }^{54}$ RAW 264.7 cells were incubated with DiI-labeled self-assembled NPs and EM-NPs, and visualized using inverted fluorescence microscopy (figure 3A) and a flow cytometry (figure 3B). Results showed that the self-assembled NPs exhibited stronger red fluorescence when compared with EM-NPs, thus demonstrating after coating erythrocyte membranes, uptake of NPs in RAW 264.7 cells significantly reduced, which undoubtedly improved the effective delivery of antigenic peptides.

A

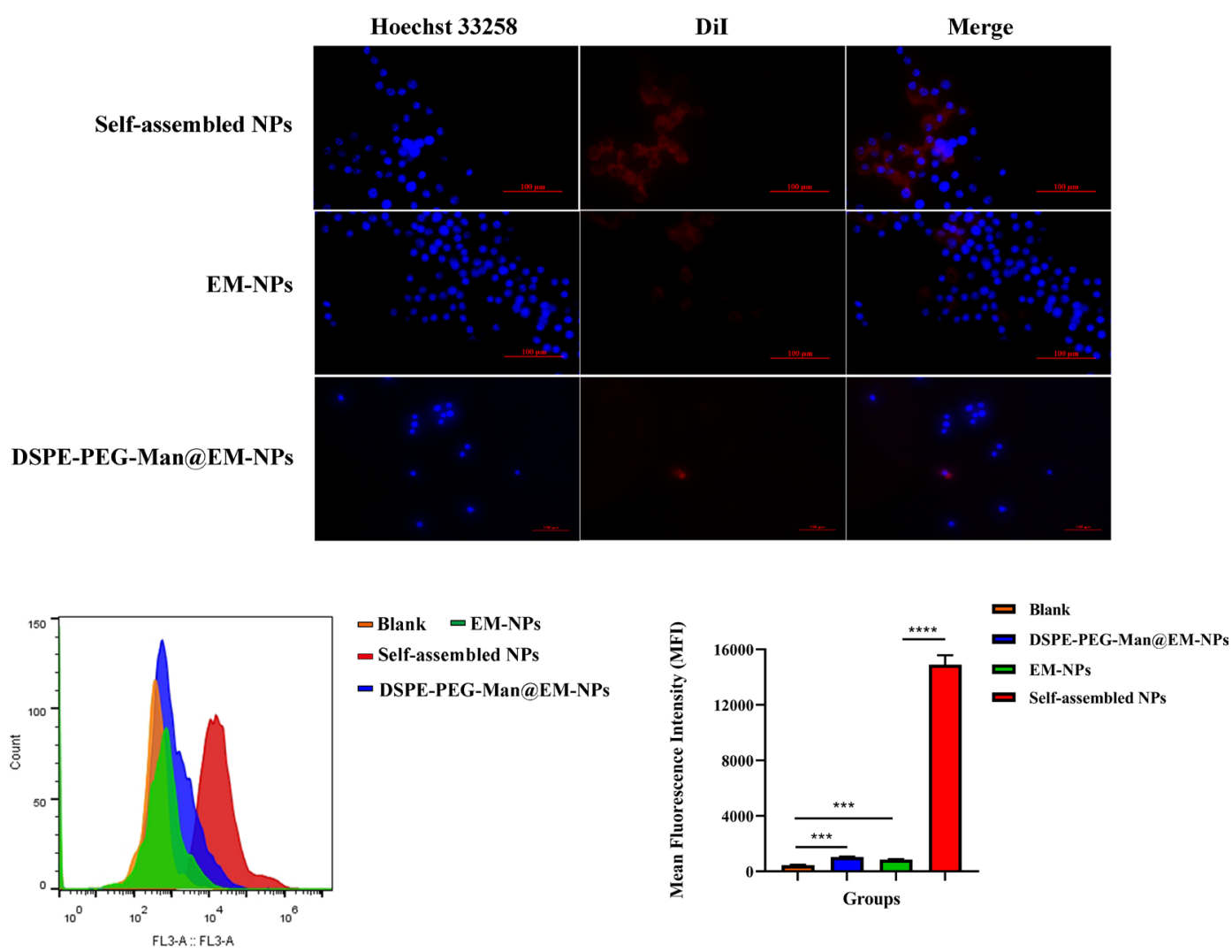

Figure 3 (A) Intracellular uptake of self-assembled NPs and EM-NPs in RAW264.7 cells determined by an inverted fluorescence microscopy after 4-hour incubation. The nucleus was stained with Hoechst 33258 (blue). The self-assembled NPs, EM-NPs and DSPE-PEG-Man@EM-NPs were labeled with Dil (red). (B) Mean intracellular fluorescence intensity in RAW264.7 cells after 4-hour incubation with Dil-stained self-assembled NPs, EM-NPs and DSPE-PEG-Man@EM-NPs determined by a flow cytometry, ${ }^{* \star *} \mathrm{p}<0.0001,{ }^{* \star \star *} \mathrm{p}<0.0001$ and experiments were performed in triplicate. NPs, nanoparticles. 
A
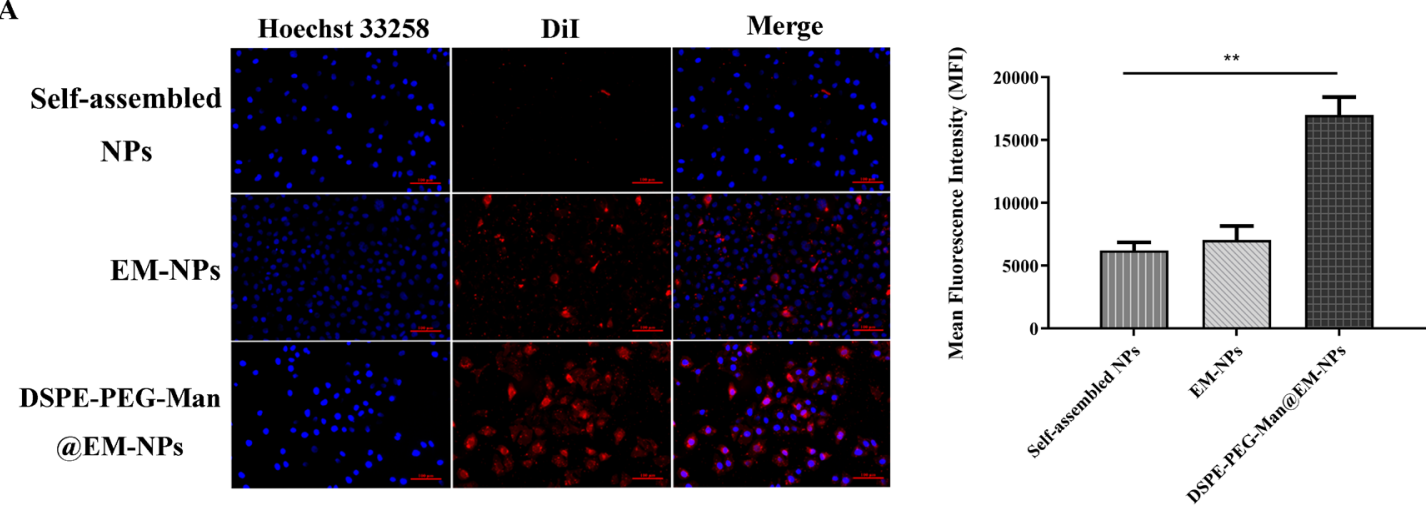

B

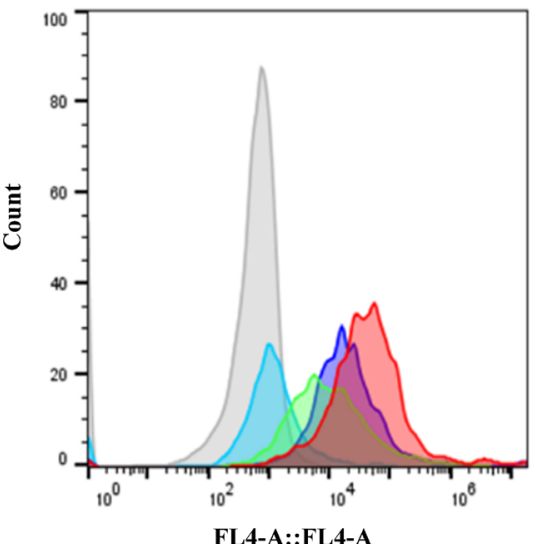

- Blank $\square$ Control

- Self-assembled NPs

- EM-NPs

= DSPE-PEG-Man@EM-NPs

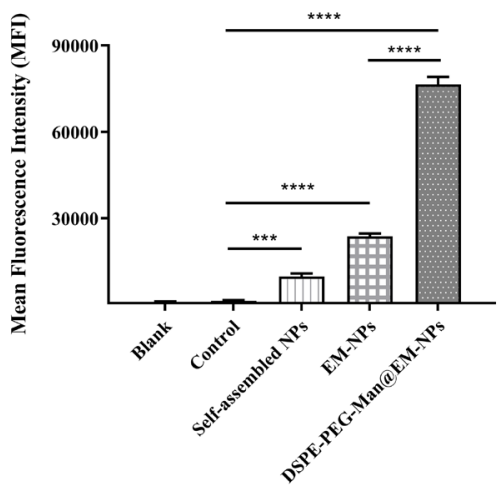

C
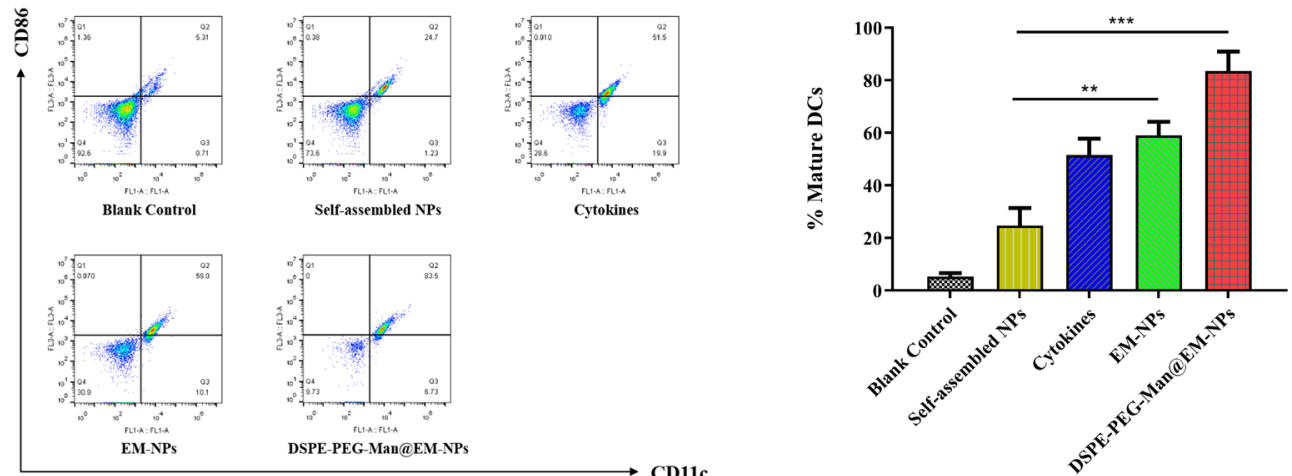

Figure 4 Evaluation of the ability of NPs to be ingested by DCs and promoting DCs maturation. (A) The uptake of NPs by DCs was determined by an inverted fluorescence microscopy and (B) a flow cytometry; (C) detection of CD11c, CD86 and the mature rates of DCs induced by different NPs, ${ }^{* *} \mathrm{p}<0.01,{ }^{* * *} \mathrm{p}<0.001,{ }^{* * *} \mathrm{p}<0.0001$ and experiments were performed in triplicate. DCs, dentritic cells; NPs, nanoparticles.

\section{Targeting properties of DSPE-PEG-Man@EM-NPs to DCs}

The uptake of DSPE-PEG-Man@EM-NPs by DCs was observed using an inverted fluorescence microscopy and a flow cytometry. The NPs were labeled with DiI (red dye) and the nucleus were surrounded with Hoechst 33258 (blue fluorescence). Results as described in figure 4A,B, there were clear differences among the uptake of selfassembled NPs, EM-NPs and DSPE-PEG-Man@EM-NPs. The intensity of red and blue superposition in DSPEPEG-Man@EM-NPs was the strongest under a fluorescence microscope, and the average fluorescence intensity in cells was also most significant by a flow cytometry. Meanwhile, to further demonstrate that the targeting ability that resulted from mannose, the uptake ability of DCs to DSPE-PEG-Man@NPs was compared with the control group which was pre-emptive with mannose (online supplemental figure $\mathrm{S} 1$ ). In the pre-emptive group, the uptake of DCs to DSPE-PEG-Man@NPs was significantly reduced. This suggested mannose-mediated receptor targeting could greatly enhance the targeted uptake to DCs.

\section{Maturation of DCs induced by NPs}

Previous studies have shown that antigenic peptides can promote the maturation of DCs to some extent. ${ }^{27}{ }^{55} \mathrm{In}$ terms of DCs maturation function of DSPE-PEG-Man@ EM-NPs, visual observation from the morphology showed that with the processing of culture, the number of 
A

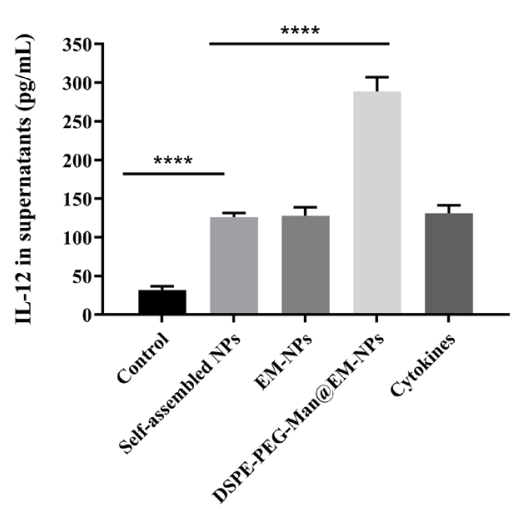

C

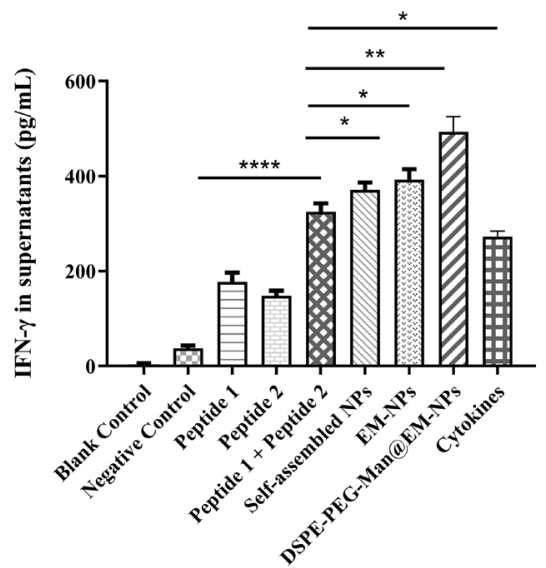

B

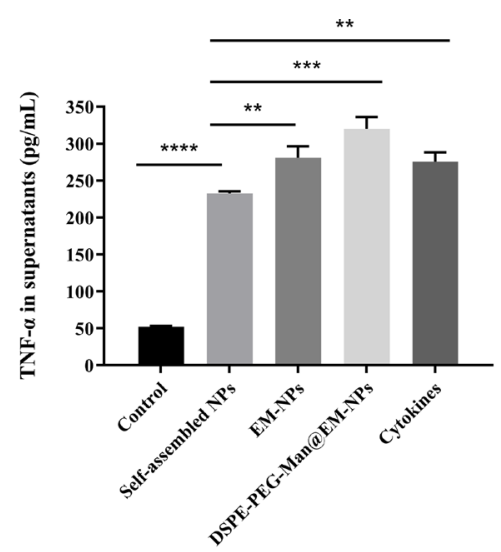

D

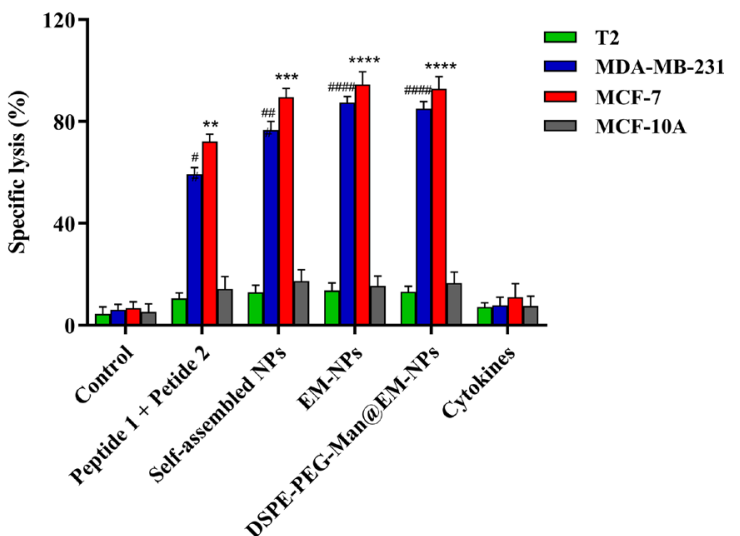

Figure 5 Determination of IL-12 level in the supernatant, activation of CD8+T lymphocytes and evaluation of CTLs' ability to kill target cells in vitro. (A) Determination of IL-12 level in the supernatant, which was used as another important indicator for DCs maturity, ${ }^{* \star \star *} \mathrm{p}<0.0001 ;(\mathrm{B}, \mathrm{C})$ determination of TNF- $\alpha$ and IFN- $\gamma$ level in the supernatant, which was used as important indicators for CD8 +T lymphocytes activation, ${ }^{\star} \mathrm{p}<0.05 ;{ }^{* *} \mathrm{p}<0.01 ;{ }^{* \star *} \mathrm{p}<0.001 ;{ }^{* \star * *} \mathrm{p}<0.0001$; (D) determination of specific lysis

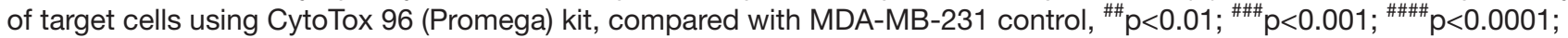
compared with MCF-7 control, ${ }^{* *} \mathrm{p}<0.01 ;{ }^{* \star *} \mathrm{p}<0.001 ;{ }^{* \star * *} \mathrm{p}<0.0001$ and experiments were performed in triplicate. CTLs, cytotoxic T lymphocytes; DCs, dentritic cells; IFN- $\gamma$, interferon gamma; IL-12, interleukin 12; TNF- $\alpha$, tumor necrosis factor- $\alpha$.

suspended cells gradually increased, the cell membranes protruded from the root like bulge, and the cells became larger and more clustered. To study the effects of NPs on the maturation of DCs, peripheral blood-derived DCs were isolated and cultured in vitro, stimulated with IL-4 and GM-CSF, and then stimulated with different groups of NPs. After 24hours, cytometry was used to determine the expression of CD86 and CD11c molecules on the surface of DCs. Compared with the control group, the self-assembled NPs, EM-NPs, and DSPE-PEG-Man@ EM-NPs significantly promoted the expression of CD86 and $\mathrm{CD} 11 \mathrm{c}$, and the effect was comparable to or even better than cytokines (figure 4C). Additionally, another important indicator to determine the maturity of DCs is the secretion of IL-12 in supernatant. From figure 5A, we can see that IL-12 in the supernatant of each experimental group was significantly increased when compared with the control group $(35 \mathrm{pg} / \mathrm{mL})(\mathrm{p}<0.0001)$, among which the IL-12 of DSPE-PEG-Man@EM-NPs group was the highest (up to about $300 \mathrm{pg} / \mathrm{mL}$ ). All these results coincided with each other and showed that DSPE-PEG-Man@ EM-NPs could well promote the maturity of DCs.

\section{Significant activation of CD8 ${ }^{+}$T lymphocytes by NPs: IFN- $\gamma$ and TNF- $\alpha$ in the supernatant}

Activation of $\mathrm{CD}^{+} \mathrm{T}$ lymphocytes is strictly regulated by DCs, and DCs loaded with antigenic peptide can further promote the activation function. The important indicator of CD8 + T lymphocytes activation is the secretion of IFN- $\gamma$ and TNF- $\alpha$. On the one hand, IFN- $\gamma$ and TNF- $\alpha$ can stimulate the expression of MHC molecules on the surface of target cells to enhance antigens presentation. On the other hand, they would be beneficial to the phagocytosis of DCs. Here, DCs treated with different NPs were incubated with $\mathrm{CD}^{+} \mathrm{T}$ lymphocytes for 24 hours, the secretion of IFN- $\gamma$ in the supernatant was detected by ELISA kit, and the effect on the activation of $\mathrm{CD}^{+} \mathrm{T}$ lymphocytes was evaluated. Significantly, we first investigated the effects of Pep1 and Pep2 derived from two different antigens, and it has been confirmed that the combination of Pep1 and Pep2 basically only plays a role on their respective targets, but does not show the influence of each other on tumor inhibition (IFN- $\gamma$ (sole pep1 group: $177.02 \pm 19.72 \mathrm{pg} / \mathrm{mL}$; sole pep2 group: $148.37 \pm 10.55 \mathrm{pg} /$ $\mathrm{mL}$; pep1 + pep2 group: $325.27 \pm 23.43 \mathrm{pg} / \mathrm{mL}$ ). Moreover, 


\section{MDA-MB-231}

A

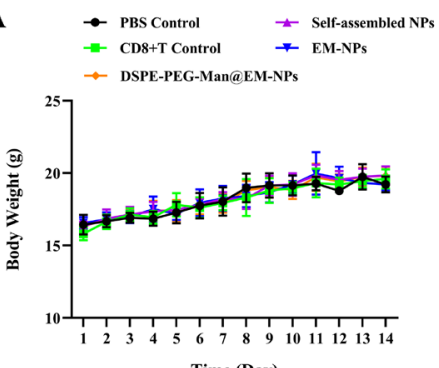

C

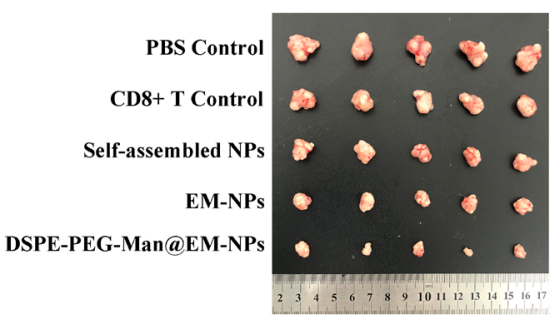

B
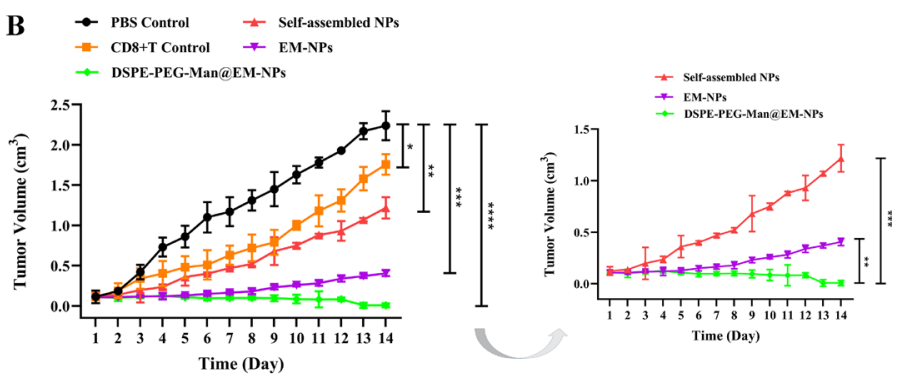

D

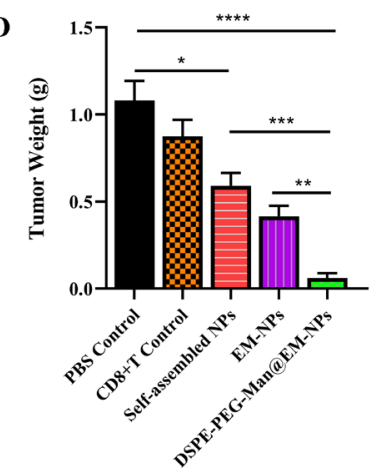

E

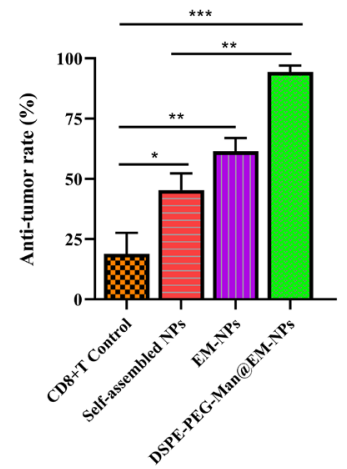

Figure 6 In vivo tumor inhibition experiment in MDA-MB-231 models, $n=5$ mice per group. (A) Weight changes in mice within 2 weeks after treatment; (B) tumor growth curves of different groups of tumors after various treatments; (C) the sizes of dissected tumor tissues in each group; (D) the tumor weight in all groups compared with each other on the 14th day; $(E)$ analysis of tumor inhibition rate in each group. ${ }^{*} \mathrm{P}<0.05 ;{ }^{* *} \mathrm{p}<0.01 ;{ }^{* * \star} \mathrm{p}<0.001 ;{ }^{* * \star} \mathrm{p}<0.0001$. NPs, nanoparticles; PBS, phosphate buffered solution;

significant increases in the levels of TFN- $\alpha$ and IFN- $\gamma$ in the groups of self-assembled NPs, EM-NPs, and DSPEPEG-Man@EM-NPs were observed with significant differences compared with the control group (figure 5B,C).

\section{Activation of CTLs by NPs}

In order to evaluate the in vitro specific killing of CTLs to target cells after stimulation with different NPs, we used $\mathrm{CD} 8^{+} \mathrm{T}$ lymphocytes and DCs treated with different NPs at the ratio of 1:5 as effector cells. T2 cells, MCF-7 cells, MDA-MB-231 cells, and MCF-10A cells were used as target cells. The mixture of online supplemental peptides 1 and 2 as well as all other prepared NPs had a certain degree of lethality to MCF-7 and MDA-MB-231 cells, among which EM-NPs and DSPE-PEG-Man@EM-NPs showed the best effect: the killing rate against MCF-7 was $94.5 \% \pm 5.03 \%$ and $87.4 \% \pm 2.46 \%$, respectively, and the killing rate against MDA-MB-231 was $92.8 \% \pm 4.77 \%$ and $85.0 \% \pm 2.85 \%$, respectively (figure $5 \mathrm{D}$ ).

\section{In vivo antitumor effect of NPs}

The results were exhibited in figures 6 and 7. Consistent results were obtained to those from in vitro experiments. No sudden change of mice weights was observed within the 2 weeks. Compared with the PBS group (blank control) and $\mathrm{CD}^{+} \mathrm{T}$ lymphocytes group (negative control), all the three measured NPs groups showed a certain tumor inhibition effect in vivo. Among them, the best inhibition effect was performed in the group of DSPE-PEG-Man@
EM-NPs of which the tumor inhibition rate in MDAMB-231 and MCF-7 models was both nearly 90\%, which significantly inhibited tumor growth with compared with the self-assembled NPs and PBS control group.

\section{Systemic toxicity in vivo}

MTT assay was carried out to determine the toxicity of different NPs on DCs and other target cells, so as to exclude the self-toxicity effect of NPs on the antitumor activity and determine their safety. Results were shown in table 1, 24 hours after incubation, the survival rate of cells in each group was still more than $85 \%$, thereby indicating a negligible toxicity of NPs themselves. Additionally, H\&E staining was performed on the tumor tissue sections of each group (figure 8). The tumors in the saline group showed large nuclear staining, deep staining, clear outline, large nuclear ratio, rare tumor necrosis, and less intercellular substance, while those in each experimental group were sparsely distributed, demonstrating different degrees of apoptosis and necrosis. The most significant apoptosis and necrosis were observed in the group of DSPE-PEG-Man@EM-NPs. Thereafter, no pathological change was found in the histological stainings of liver, kidney, lung, and spleen, thus suggesting that the as-constructed nanodelivery system is safe and effective.

\section{Conclusions and discussion}

The self-assembled NPs with different antigenic peptides (online supplemental peptides 1 and 2) were first 
MCF-7
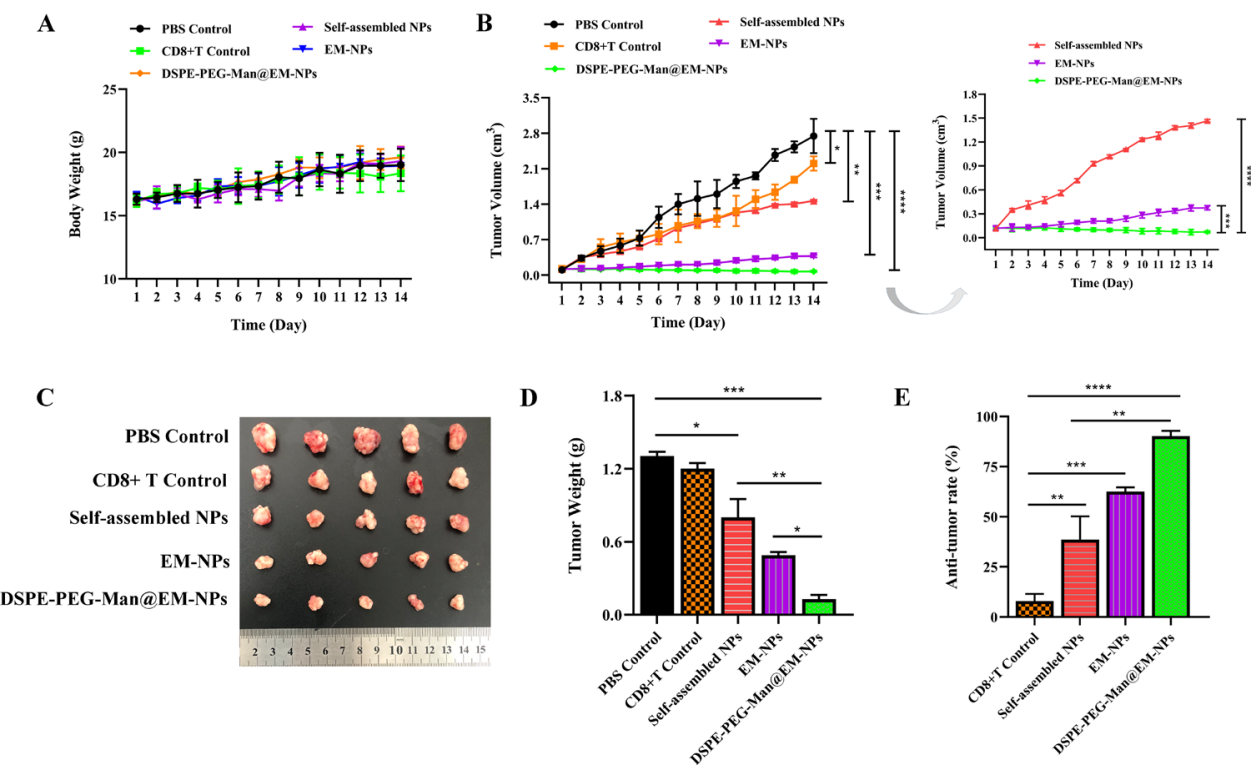

Figure 7 In vivo tumor inhibition experiment in MCF-7 models, $\mathrm{n}=5$ mice per group. (A) Weight changes in mice within 2 weeks after treatment; (B) tumor growth curves of different groups of tumors after various treatments; (C) the size of dissected tumor tissues in each group; (D) the tumor weight in all groups compared with each other on the 14th day; (E) analysis of tumor inhibition rate in each group. ${ }^{\star} \mathrm{P}<0.05$; ${ }^{\star \star} \mathrm{p}<0.01$; ${ }^{\star \star \star} \mathrm{p}<0.001$; ${ }^{\star \star \star \star} \mathrm{p}<0.0001$. NPs, nanoparticles; PBS, phosphate buffered solution.

developed. These NPs not only enlarged the response range within the same molecule but also significantly prolonged the plasma half-life of single antigenic peptides. Subsequently, the delivery system (DSPEPEG-Man@EM-NPs) was constructed by encapsulating the self-assembled NPs with DCs-targeted erythrocyte membranes. This delivery system successfully avoided the phagocytosis of the self-assembled NPs by macrophages, improved the capture efficiency of antigenic peptides to DCs, and further enhanced the immune response rate, which is essential for treating patients with breast cancer in the future. Importantly, the as-prepared DSPEPEG-Man@EM-NPs successfully expanded the treatment range of antigen peptides from a single MDA-MB-231 or MCF-7 type to the compatible type (in both models, the tumor inhibition rate reached nearly 90\%), and the half-lives of peptides were extended by three times. However, throughout the current research on the immunotherapy strategy of breast cancer, there are still much serious challenges to be solved, such as the low efficiency of recognizing target antigens and tumors, the existence of resistance in tumor microenvironment as well as in different types of breast cancer. How to reasonably plan the treatment and develop a reliable and cost-effective immunotherapy platform will become the focus. Considering the above problems, the treatments dominated by antigenic peptides will play a significant role in clinical practice. Through a simple blood test and an in vivo biopsy, phenotypes of HLA-A2 and tumor antigens of patients could be identified. At that time, the system could also be wrapped and modified with the autologous erythrocyte membranes. This system would be used to deliver the bi-antigenic peptides nano-system to DCs in a targeted manner in the patients' systemic circulations, so as to perform an effective and safe role in tumor inhibition. Moreover, in future research, we would like to design a more diverse combination of antigenic peptides and adjuvant/immunomodulator, expecting to expand the treatment scope and effectively avoiding immune failure caused by antigenic mutation. Generally, compared with the effect of completely eliminating tumors, it has more significance to provide an innovative thought to assemble

Table 1 Cytotoxicity of different NPs on target cells (each group was tested three times in parallel)

\begin{tabular}{llllll}
\hline Compounds & Viability (\%) & & & & \\
\hline (100 $\boldsymbol{\mu M})$ & MCF-7 & MDA-MB-231 & MCF-10A & T2 & DCs \\
\hline Self-assembled NPs & $>100$ & $97.44 \pm 6.83$ & $>100$ & $93.26 \pm 4.91$ & $>100$ \\
EM-NPs & $>100$ & $95.38 \pm 5.84$ & $99.26 \pm 5.06$ & $97.21 \pm 3.80$ & $>100$ \\
DSPE-PEG-Man@EM-NPs & $>100$ & $>100$ & $>100$ & $93.83 \pm 4.88$ & $>100$ \\
\hline
\end{tabular}

DCs, dentritic cells; NPs, nanoparticles. 

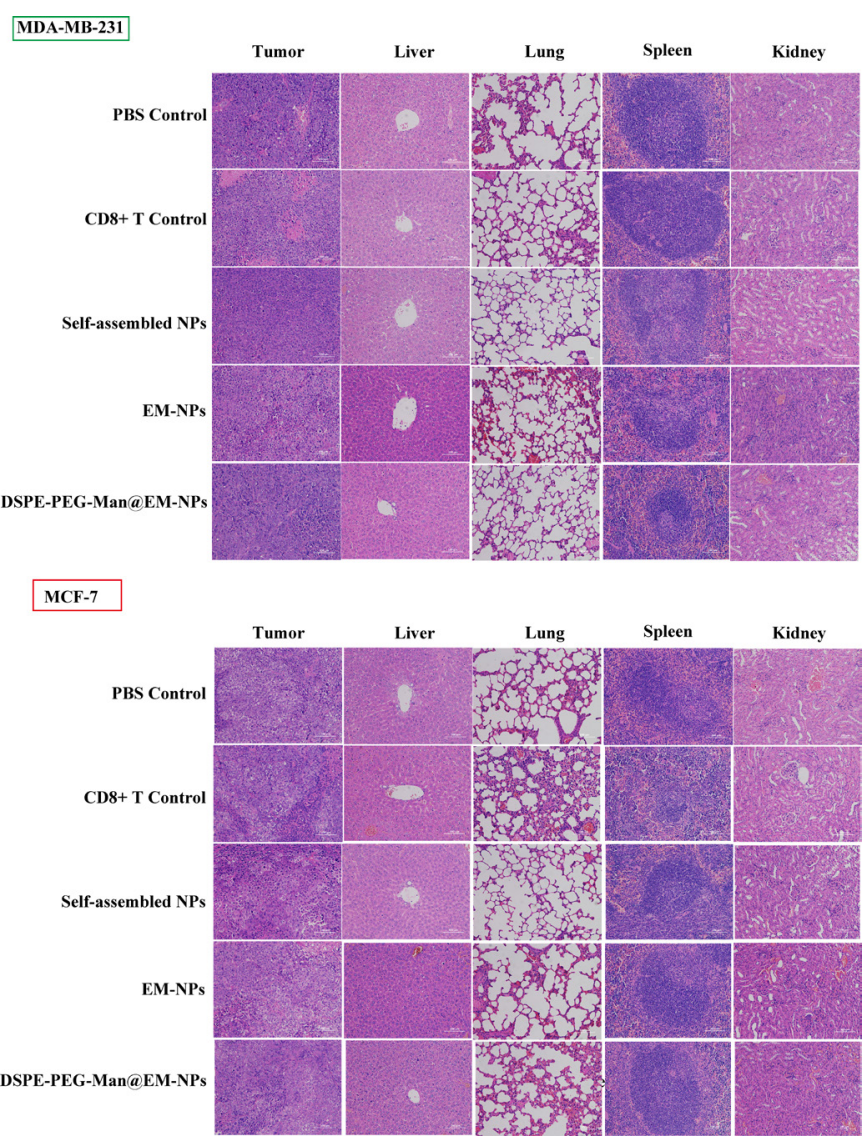

Figure 8 Representative images of histopathological analysis of tumors and important organs from mice treated with different NPs, and images were enlarged 200 times with the microscope, and the scale was $100 \mu \mathrm{m}$. PBS, phosphate buffered solution; NPs, nanoparticles.

some antigenic peptides from various genes, and even neoantigens, which is likely to reduce the difficulty of accuracy, effectively avoid escape phenomenon, and then achieve the ideal effect.

\section{Statistical analysis}

Data were presented as mean $\pm \mathrm{SD}$. The one-way analysis of variance was performed in statistical evaluation. A $p$ value below $0.05\left({ }^{*} \mathrm{p}<0.05,{ }^{* *} \mathrm{p}<0.01,{ }^{* * * *} \mathrm{p}<0.001,{ }^{* * * *} \mathrm{p}<0.0001\right)$ was considered to be statistically significant.

\section{Supporting information}

Supporting Information is available from the Wiley Online Library or from the author.

\section{Author affiliations \\ ${ }^{1}$ Center of Drug Discovery, State Key Laboratory of Natural Medicines, China Pharmaceutical University, 24 Tongjiaxiang, Nanjing 210009, China ${ }^{2}$ School of Pharmacy, Jiangsu Provincial Key Laboratory of Coastal Wetland Bioresources and Environmental Protection, Yancheng Teachers' University, Yancheng 224002, China \\ ${ }^{3}$ Jiangsu Key Laboratory of Drug Discovery for Metabolic Disease, China Pharmaceutical University, 24 Tongjiaxiang, Nanjing 210009, Jiangsu, China}

Contributors WS, HQ, and QQ conceived and designed research; WS, ZF, and ZT performed experiments; WS, FZ analyzed data; WS, NY and WH interpreted results of experiments; WS and QQ prepared figures; WS and WG drafted manuscript; all authors approved the content of the final version of manuscript.

Funding We thank the support from National Natural Science Foundation of China (Nos. 81872733, 81872734, and 81673299) and the China Postdoctoral Science Foundation (No. 2020M681792).

Competing interests None declared.

Patient consent for publication Not required.

Ethics approval All the blood-related experimental protocols and experimental protocols for animals in this study were approved by an ethical committee at the China Pharmaceutical University, conducted according to related laws and regulations as well as the Laboratory Animal Management Regulations in China and adhered to the Guide for the Care and Use of Laboratory Animals published by the National Institutes of Health (revised 2011).

Provenance and peer review Not commissioned; externally peer reviewed.

Data availability statement All data relevant to the study are included in the article or uploaded as online supplemental information.

Supplemental material This content has been supplied by the author(s). It has not been vetted by BMJ Publishing Group Limited (BMJ) and may not have been peer-reviewed. Any opinions or recommendations discussed are solely those of the author(s) and are not endorsed by BMJ. BMJ disclaims all liability and responsibility arising from any reliance placed on the content. Where the content includes any translated material, BMJ does not warrant the accuracy and reliability of the translations (including but not limited to local regulations, clinical guidelines, terminology, drug names and drug dosages), and is not responsible for any error and/or omissions arising from translation and adaptation or otherwise.

Open access This is an open access article distributed in accordance with the Creative Commons Attribution Non Commercial (CC BY-NC 4.0) license, which permits others to distribute, remix, adapt, build upon this work non-commercially, and license their derivative works on different terms, provided the original work is properly cited, appropriate credit is given, any changes made indicated, and the use is non-commercial. See http://creativecommons.org/licenses/by-nc/4.0/.

\section{ORCID iD}

Hai Qian http://orcid.org/0000-0002-3827-0992

\section{REFERENCES}

1 Emens LA. Breast cancer immunotherapy: facts and hopes. Clin Cancer Res 2018;24:511-20.

2 Harbeck N, Gnant M. Breast cancer. Lancet 2017;389:1134-50.

3 Seguin L, Desgrosellier JS, Weis SM, et al. Integrins and cancer: regulators of cancer stemness, metastasis, and drug resistance. Trends Cell Biol 2015;25:234-40.

4 Hjorth CF, Nielsen AS, Sørensen HT, et al. Multi-Drug resistance protein 2 (MRP2) expression, adjuvant tamoxifen therapy, and risk of breast cancer recurrence: a Danish population-based nested casecontrol study. Acta Oncol 2019;58:168-74.

5 Bollig-Fischer A, Dewey TG, Ethier SP. Oncogene activation induces metabolic transformation resulting in insulin-independence in human breast cancer cells. PLoS One 2011;6:e17959.

6 Esteva FJ, Hubbard-Lucey VM, Tang J, et al. Immunotherapy and targeted therapy combinations in metastatic breast cancer. Lancet Oncol 2019;20:e175-86.

7 Al-Awadhi A, Lee Murray J, Ibrahim NK. Developing anti-HER2 vaccines: breast cancer experience. Int J Cancer 2018;143:2126-32.

8 Colomer R. [Vaccines and breast cancer]. Med Clin 2008;131:692-3.

9 Wang J, Zhou P. New approaches in CAR-T cell immunotherapy for breast cancer. Adv Exp Med Biol 2017;1026:371-81.

10 Su M, Huang C-X, Dai A-P. Immune checkpoint inhibitors: therapeutic tools for breast cancer. Asian Pac J Cancer Prev 2016;17:905-10.

11 Tam JP. Synthetic peptide vaccine design: synthesis and properties of a high-density multiple antigenic peptide system. Proc Natl Acad Sci U S A 1988;85:5409-13.

12 Anasir MI, Poh CL. Advances in antigenic peptide-based vaccine and neutralizing antibodies against viruses causing hand, foot, and mouth disease. Int J Mol Sci 2019;20:1256.

13 Li Y, Wang W, Jia $\mathrm{X}$, et al. A targeted multiple antigenic peptide vaccine augments the immune response to self TGF- $\beta 1$ and suppresses ongoing hepatic fibrosis. Arch Immunol Ther Exp 2015;63:305-15. 
14 Boon T, Van Pel A, De Plaen E. Tum- transplantation antigens, point mutations, and antigenic peptides: a model for tumor-specific transplantation antigens? Cancer Cells 1989;1:25-8.

15 Boon T, Van den Eynde B, Hirsch H, et al. Genes coding for tumorspecific rejection antigens. Cold Spring Harb Symp Quant Biol 1994;59:617-22.

16 Zhang S, Zhou X, Yu H, et al. Expression of tumor-specific antigen MAGE, GAGE and BAGE in ovarian cancer tissues and cell lines. BMC Cancer 2010;10:163.

17 Ulloa-Montoya F, Louahed J, Dizier B, et al. Predictive gene signature in MAGE-A3 antigen-specific cancer immunotherapy. J Clin Oncol 2013;31:2388-95.

18 Somaiah N, Block MS, Kim JW, et al. First-In-Class, first-in-human study evaluating LV305, a dendritic-cell tropic lentiviral vector, in sarcoma and other solid tumors expressing NY-ESO-1. Clin Cancer Res 2019;25:5808-17.

19 Sun Y-Y, Peng S, Han L, et al. Local HPV recombinant vaccinia boost following priming with an HPV DNA vaccine enhances local HPVSpecific CD8+ T-cell-mediated tumor control in the genital tract. Clin Cancer Res 2016;22:657-69.

20 Okarvi SM, Al Jammaz I. Preparation and evaluation of the tumorspecific antigen-derived synthetic mucin 1 peptide: a potential candidate for the targeting of breast carcinoma. Nucl Med Biol 2016;43:403-9.

21 Eikawa S, Kakimi K, Isobe M, et al. Induction of CD8 T-cell responses restricted to multiple HLA class I alleles in a cancer patient by immunization with a 20-mer NY-ESO-1f (NY-ESO-1 91-110) peptide. Int J Cancer 2013;132:345-54.

22 Shi $\mathrm{H}$, Jiang X, Fu P, et al. Use of dentritic cells pulsed with HLA-A2restricted MAGE-A1 peptide to generate cytotoxic T lymphocytes against malignant glioma. J Huazhong Univ Sci Technolog Med Sci 2010;30:678-82.

23 Rahma OE, Herrin VE, Ibrahim RA, et al. Pre-immature dendritic cells (PIDC) pulsed with HPV16 E6 or E7 peptide are capable of eliciting specific immune response in patients with advanced cervical cancer. $J$ Trans/ Med 2014;12:353.

24 Ho CK, Babiuk LA. Immune mechanisms against canine distemper. II. Role of antibody in antigen modulation and prevention of intercellular and extracellular spread of canine distemper virus. Immunology 1979;38:765-72.

25 Cruz-Leal Y, Marjoram D, Lazarus AH. Erythrocyte saturation with IgG is required for inducing antibody-mediated immune suppression and impacts both erythrocyte clearance and Antigen-Modulation mechanisms. J Immunol 2018;200:1295-305.

26 Wan J, Liu W, Xu Q, et al. SVRMHC prediction server for MHCbinding peptides. BMC Bioinformatics 2006;7:463.

27 Shi W, Qiu Q, Tong Z, et al. Synthetic tumor-specific antigenic peptides with a strong affinity to HLA-A2 elicit anti-breast cancer immune response through activating $\mathrm{CD} 8^{+} \mathrm{T}$ cells. Eur $\mathrm{J}$ Med Chem 2020;189:112051.

28 Shi W, Tong Z, Qiu Q, et al. Novel HLA-A2 restricted antigenic peptide derivatives with high affinity for the treatment of breast cancer expressing NY-ESO-1. Bioorg Chem 2020;103:104138.

29 Zhang R, Billingsley MM, Mitchell MJ. Biomaterials for vaccinebased cancer immunotherapy. J Control Release 2018;292:256-76.

30 Rahat MA. Targeting angiogenesis with peptide vaccines. Front Immunol 2019;10:10.

31 Martiñón S, Cisneros A, Villicaña S, et al. Chemical and immunological characteristics of Aluminum-Based, oil-water emulsion, and Bacterial-Origin adjuvants. J Immunol Res 2019;2019:1-9.

32 Gu P, Wusiman A, Wang S, et al. Polyethylenimine-coated PLGA nanoparticles-encapsulated Angelica sinensis polysaccharide as an adjuvant to enhance immune responses. Carbohydr Polym 2019;223:115128.

33 Pan Y, Qi Y, Shao N, et al. Amino-Modified polymer nanoparticles as adjuvants to activate the complement system and to improve vaccine efficacy in vivo. Biomacromolecules 2019;20:3575-83.
34 Liu K, Victora GD, Schwickert TA, et al. In vivo analysis of dendritic cell development and homeostasis. Science 2009;324:392-7.

35 Chen D, Koropatnick J, Jiang N, et al. Targeted siRNA silencing of indoleamine 2, 3-dioxygenase in antigen-presenting cells using mannose-conjugated liposomes: a novel strategy for treatment of melanoma. J Immunother 2014;37:123-34.

36 White KL, Rades T, Furneaux RH, et al. Mannosylated liposomes as antigen delivery vehicles for targeting to dendritic cells. J Pharm Pharmacol 2006;58:729-37.

37 Abed N, Saïd-Hassane F, Zouhiri F, et al. An efficient system for intracellular delivery of beta-lactam antibiotics to overcome bacterial resistance. Sci Rep 2015;5:13500.

38 Xu P, Wang R, Wang X, et al. Recent advancements in erythrocytes, platelets, and albumin as delivery systems. Onco Targets Ther 2016:9:2873-84.

39 Rao L, Xu J-H, Cai B, et al. Synthetic nanoparticles camouflaged with biomimetic erythrocyte membranes for reduced reticuloendothelial system uptake. Nanotechnology 2016;27:085106.

40 Guo Y, Wang D, Song Q, et al. Erythrocyte Membrane-Enveloped polymeric nanoparticles as Nanovaccine for induction of antitumor immunity against melanoma. ACS Nano 2015;9:6918-33.

41 Gao M, Liang C, Song X, et al. Erythrocyte-Membrane-Enveloped perfluorocarbon as nanoscale artificial red blood cells to relieve tumor hypoxia and enhance cancer radiotherapy. Adv Mater 2017;29:1701429.

42 Yang Q, Xiao Y, Yin Y, et al. Erythrocyte Membrane-Camouflaged IR780 and DTX Coloading polymeric nanoparticles for imagingguided cancer Photo-Chemo combination therapy. Mol Pharm 2019;16:3208-20.

43 Kolesnikova TA, Skirtach AG, Möhwald H. Red blood cells and polyelectrolyte multilayer capsules: natural carriers versus polymerbased drug delivery vehicles. Expert Opin Drug Deliv 2013;10:47-58.

44 Kaizuka Y, Douglass AD, Vardhana S, et al. The coreceptor CD2 uses plasma membrane microdomains to transduce signals in T cells. $J$ Cell Biol 2009;185:521-34

45 Xie X, Wang H, Williams GR, et al. Erythrocyte membrane Cloaked Curcumin-Loaded nanoparticles for enhanced chemotherapy. Pharmaceutics 2019;11:429.

46 Wang B, An J, Zhang $\mathrm{H}$, et al. Personalized Cancer Immunotherapy via Transporting Endogenous Tumor Antigens to Lymph Nodes Mediated by Nano $\mathrm{Fe}_{3} \mathrm{O}_{4}$. Small 2018;14:e1801372.

47 Beynon V, Quintana FJ, Weiner HL. Activated human CD4+CD45RO+ memory T-cells indirectly inhibit NLRP3 inflammasome activation through downregulation of P2X7R signalling. PLoS One 2012;7:e39576.

48 Burster T, Beck A, Tolosa E, et al. Differential processing of autoantigens in lysosomes from human monocyte-derived and peripheral blood dendritic cells. J Immunol 2005;175:5940-9.

49 Mancuso G, Gambuzza M, Midiri A, et al. Bacterial recognition by TLR7 in the lysosomes of conventional dendritic cells. Nat Immunol 2009;10:587-94.

50 Kroll AV, Fang RH, Jiang Y, et al. Nanoparticulate delivery of cancer cell membrane elicits Multiantigenic antitumor immunity. Adv Mater 2017;29:1703969-26.

51 Xia Q, Zhang Y, Li Z, et al. Red blood cell membrane-camouflaged nanoparticles: a novel drug delivery system for antitumor application. Acta Pharm Sin B 2019;9:675-89.

52 Hahn WC, Menu E, Bothwell AL, et al. Overlapping but nonidentical binding sites on CD2 for CD58 and a second ligand CD59. Science 1992;256:1805-7.

53 Song Y, Jin J, Li J, et al. Gd@C82(OH)22 nanoparticles constrain macrophages migration into tumor tissue to prevent metastasis. $J$ Nanosci Nanotechnol 2014;14:4022-8.

54 Chen W, Zeng K, Liu H, et al. Cell membrane camouflaged hollow Prussian blue nanoparticles for synergistic Photothermal-/ Chemotherapy of cancer. Adv Funct Mater 2017;27:1605795.

55 Telusma G, Datta S, Mihajlov I, et al. Dendritic cell activating peptides induce distinct cytokine profiles. Int Immunol 2006;18:1563-73. 